\title{
Leprosy in Barotseland
}

The Barotse Province of Northern Rhodesia forms the extreme western part of that province. Through its centre flows the Zambesi river joined by many large tributories. Regarding this province the Director of Medical Services writes:- "It has been calculated that about 2 per cent. of the population of the Barotse Province, especially in the Balovale District, are lepers, and in consequence the Government evolved a scheme known as the 'Occupational Scheme for Lepers' which was intended to encourage those infected to present themselves for treatment and to keep them occupied. The scheme has proved to be very popular, even cases in the early stage of infection appearing for treatment."

We have received the following account from Mbikusita A. Godwin, care of the Paramount Chief's Office, Lealui :"Many people in Barotseland are suffering very much from leprosy, and it appears that this serious disease is increasing instead of decreasing. Therefore we should ask ourselves why does it increase and how can it be decreased?

" There are people of one family, who are, most of them, suffering from leprosy, and by that they think that they are being bewitched by a neighbour. The reasons that bring such misfortune are:-

(1) When a relative or friend is affected by this disease his friends or relatives share food with him from the same dish (using their own hands).

(2) A Mulozi does not hesitate in lending a blanket, shirt or hat to a leper when he is related to him. 
(3) When a Mulozi meets a. leper (friend or relative) he does not hesitate in kissing him, never mind whether the spot to be kissed is actually affected.

(4) A leper can be asked to occupy any chair or mat in the house without hesitation.

Some people, most especially educated ones, do all these by flattering, they very well know that by allowing these they are actually poisoning themselves, but they don't want to disappoint their friends or relatives.

"The only thing that can help very much in decreasing this disease is an Hospital that can be built specially for those who are suffering from this disease. GoD HELPS THOSE WHO HELP THEMSELVES. If an agreement, after arrangement, can be made to have such a Hospital in Barotseland, every Mulozi, male and female, should subscribe something towards its establishment, and instead of being optional, the subscription should be compulsory, because the Hospital will be beneficial to all. Women may bring baskets of maize or mwanja meal for their subscription, which can be sold quite easily. Such subscription should be an annual one to be run for three or more years. It takes time to make a good business. It is bad for us to put all loads upon the Government. If the Government and other European friends may like to help us in this connection, they can do that after we ourselves have established a fund. Although Barotseland is a little child and the Government is its parent, this child must be a growing one, which should one day help its parent. When you are taught, you must show your knowledge, if you don't, you discourage your teacher. Your Missionaries taught you hygiene, therefore don't neglect that knowledge.

"The Hospitals that we have at Mongu and Balovale cannot adequately accommodate all those who are suffering from leprosy. Any attempt, at this moment, to do so, will create a sudden shortage of food. They can only be accommodated by a Special Hospital to be situated far from villages where they may be allowed to make gardens (those who are able to do so).

"This is a cry to all you Barotse people at home and abroad. Something good is required to free us from this enemy, otherwise thousands of souls will perish, which will mean depopulation of the whole country.

"This is a suggestion for your consideration." 


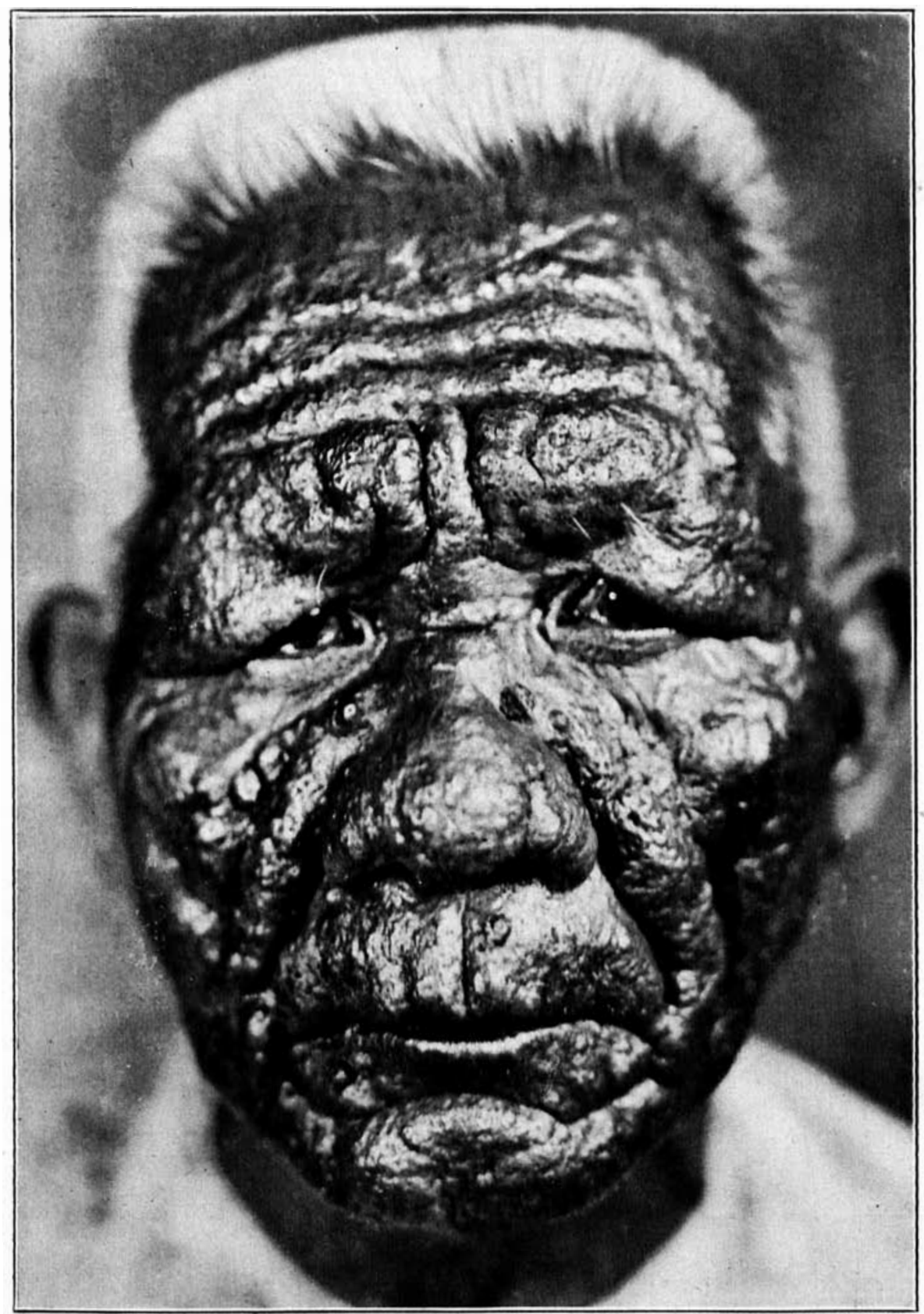

ADENOMA SEBACEUN ET ACANTHOIDES CYSTICUM, RESEMBIING LEPROSY. 


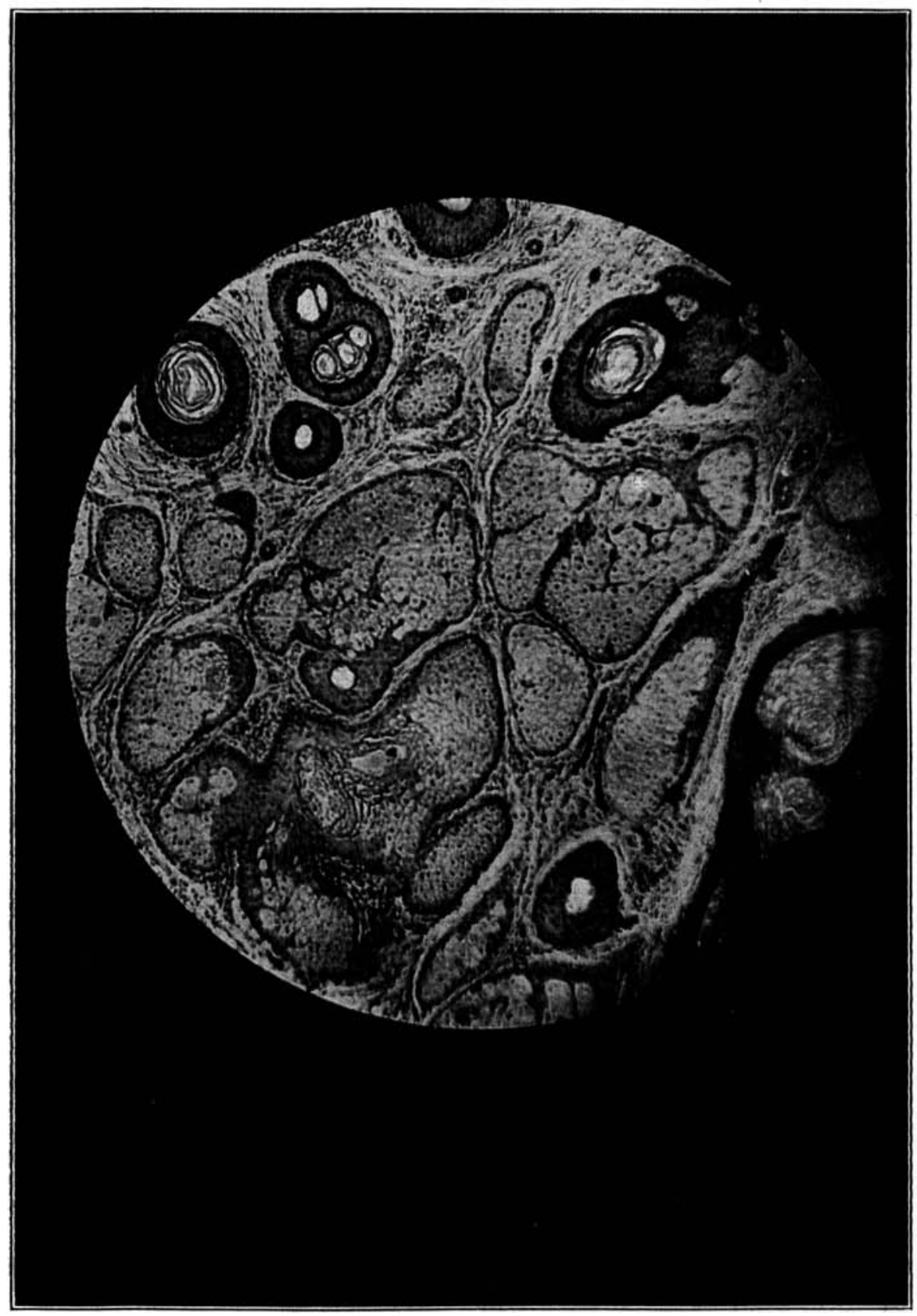

Enormous increase in number and complexity of sebaceous glands together with numerous bud-like epithelial prolongations developing cysts at their extremities in adenoma sebaceum et acanthoides cysticum, clinically resembling leprosy. 